\title{
Il campione per analisi basate su tecniche di biologia molecolare
}

\section{Marina Crovatto}

Struttura Operativa Semplice di Immunologia Clinica e Virologia

Dipartimento di Medicina di Laboratorio, Azienda Ospedaliera “Santa Maria degli Angeli”, Pordenone

\section{INTRODUZIONE}

La diagnostica microbiologica, in questi ultimi anni, ha subito profondi cambiamenti dovuti all'evoluzione delle conoscenze, alle scoperte scientifiche, agli enormi progressi tecnologici che hanno portato all'introduzione delle tecniche molecolari. Tutto ciò ha comportato vantaggi notevoli in termini di tempo e di qualità della risposta ma ha anche aperto nuove problematiche legate alla tipologia degli analiti (DNA o RNA) ed alle peculiarità delle tecniche stesse (problemi di contaminazione, presenza di inibitori delle reazioni di amplificazione ecc...). Sono molte ormai le diagnostiche molecolari consolidate, come ad esempio l'analisi quali/quantitativa dell'RNA e la genotipizzazione di HCV e HIV, il rilevamento delle resistenze ai farmaci antivirali di HIV e $\mathrm{HBV}$, il rilevamento delle mutazioni pre-core e la genotipizzazione di HBV, l'analisi quali/quantitativa del DNA di HBV, CMV ed EBV, il rilevamento degli acidi nucleici di HSV, VZV, Enterovirus, Toxoplasma, Chlamydia trachomatis, Neisseria gonorrhoeae, HPV, Legionella pneumophila, Mycobacterium tuberculosis, RSV, Adenovirus, Virus Influenza, Morbillo, Parotite + ecc... e molte sono tuttora in fase di consolidamento. Queste diagnostiche, ed in generale tutte le diagnostiche di laboratorio, sono accomunate dal materiale di partenza che è il campione biologico: è il presupposto indispensabile per l'attendibilità del risultato finale. Anche se, infatti, disponiamo delle tecniche di analisi più sofisticate ma il campione non è adeguato, il nostro risultato non potrà mai avere i requisiti di qualità sufficienti per essere utile al paziente. La fase pre-analitica pertanto rappresenta una tappa fondamentale del processo analitico. È essenziale stabilire, sulla base delle caratteristiche cliniche del paziente e delle tipologia di indagine da effettuare, la sede del prelievo del campione, il tipo di campione da prelevare, il momento in cui prelevarlo, come prelevarlo, in quale contenitore immetterlo, come trasportarlo e conservarlo $(2,4,6,7,8,9,11,12,13$, $14,15,18)$.

Campioni analizzabili con tecniche molecolari Le tecniche molecolari sono applicabili, previa opportuna standardizzazione a tutti i campioni biologici: tessuti criopreservati, paraffinati, formalinizzati, campioni bioptici, sangue, salive, feci, liquor, liquido amniotico, esfoliato endocervicale, liquido da lavaggio broncoalveolare, aspirato nasofaringeo, espettorato, tamponi (faringeo, nasofaringeo, endocervicali, vulvari, congiuntivali, liquido seminale ecc...) ecc...(1). Quando si deve analizzare siero o plasma, generalmente è peferibile il plasma in quanto in esso le quantità di acidi nucleici virali sono maggiori.

\section{Caratteristiche degli analiti}

\section{DNA}

Il DNA è una struttura stabile a temperature fisiologiche ed a temperature elevate (sono necessarie temperature superiori ai $90^{\circ} \mathrm{C}$ per denaturarlo): è il nostro patrimonio e come tale deve garantirsi la sopravvivenza anche nelle condizioni più avverse. La stabilità delle doppia elica è dovuta al fatto che le basi idrofobiche sono poste verso l'interno e vi sono molti legami deboli, tra le due eliche, che hanno una disposizione tale che la maggior parte di essi non può essere rotta senza la simultanea rottura di molti altri, cosa che difficilmente avviene (5).

\section{RNA}

L'RNA ha una struttura a singola elica, molto meno stabile del DNA, è facilmente degradabile dalle RNAsi, va incontro ad idrolisi spontanea in condizioni di $\mathrm{pH}$ e temperature elevate ed in presenza di cationi bivalenti quali lo zinco. La labilità di questa molecola è dimostrata anche dal fatto che aggiungendola al plasma non risulta amplificabile già dopo 15"(16). Sulla base di questi presupposti, quando si è cominciato a disporre di tecniche molecolari per rilevare virus quali ad esempio HCV è risultato evidente che era estremamente importante capire quanto l'acido nucleico virale fosse in grado di persistere in un campione in modo da stabilire le condizioni ottimali per garantire l'attendibilità del risultato. Sulla stabilità dell'RNA sono stati fatti numerosi studi, con risultati contrastanti:

- HCV RNA non è stabile nel siero conservato a temperatura ambiente;

- HCV RNA nel siero è stabile per almeno 4 gior- 
ni a $4^{\circ} \mathrm{C}$ ma la concentrazione diminuisce con l'aumentare della temperatura;

- HCV RNA è stabile per almeno 3 giorni sia a temperatura ambiente che a $4^{\circ} \mathrm{C}$;

- la concentrazione di HCV RNA è stabile in campioni di siero sottoposti a $3-8$ cicli di congelamento-scongelamento;

- vi sono problemi di rilevamento dell'RNA se quale anticoagulante viene utilizzata l'eparina anziché EDTA;

- HCV RNA non subisce variazioni di concentrazione nel plasma ottenuto da sangue conservato a $25^{\circ} \mathrm{C}$ per 5 giorni, con EDTA o CPDA1/EDTA;

- HCV RNA è stabile a temperatura ambiente per almeno 96 ore in provette con soluzione stabilizzante gli acidi nucleici.

De Moreau de Gerbehaye et al. (3) hanno recentemente condotto una sperimentazione su sangue proveniente da 5 pazienti con infezione da $\mathrm{HCV}$ e positività per HCV RNA. I campioni sono stati raccolti con e senza gel separatore e centrifugati 1 o 6 ore dopo la raccolta e poi mantenuti $6,24,48$, 72 o 96 ore a temperatura ambiente o a $4^{\circ} \mathrm{C}$ prima di essere sottoposti a quantizzazione dell'HCV RNA mediante Cobas Amplicor HCV Monitor Test vs. 2.0. Sono state pertanto valutati due diversi sistemi di raccolta del campione (con e senza gel separatore), due diverse modalità di conservazione (temperatura ambiente e $4^{\circ} \mathrm{C}$ ) e diversi intervalli di tempo prima del processo analitico, proprio per evidenziare l'influenza di tali possibili variabili sul risultato finale. Il logaritmo della quantità di HCV RNA non si è mai discostato dalla media oltre un valore di $\pm 0,3$. Non sono quindi state riscontrate differenze significative legate alle variabili analizzate.

I diversi studi effettuati in realtà utilizzano sistemi di raccolta e tempi di processazione diversi, per cui risulta difficile il confronto e l'ottenimento di dati sovrapponibili. Una considerazione va comunque fatta: HCV RNA è più stabile di quanto si pensasse e questo è verosimilmente spiegabile con l'effetto protettivo dell'involucro della particella virale integra. Un altro dato importante, da tener sempre presente, è che sia nel caso del DNA che dell'RNA, cicli di congelamento/scongelamento ripetuti possono determinare la perdita di quantità importanti di acido nucleico alterando pertanto i risultati delle determinazioni $(3,10)$.

Alla luce di tutte queste osservazione e delle numerose esperienze fatte anche sulla stabilità dell'acido nucleico di altri agenti patogeni (es. HIV, CMV ecc.) sono state stabilite, a seconda dei campioni e degli agenti da evidenziare, le condizioni più adeguate per poter operare correttamente. Si riportano di seguito alcuni esempi.
Ricerca qualitativa, quantitativa e genotipizzazione di HCV RNA e ricerca quantitativa di HBV DNA in campioni di sangue

La raccolta va fatta in provetta con EDTA o ACD

(mai usare eparina in quanto inibisce la reazione di amplificazione) o in provetta sterile senza anticoagulanti. In entrambi e casi si deve procedere alla centrifugazione per separare il plasma o il siero entro 6 ore dal prelievo. Il plasma ed il siero vanno stoccati in provette sterili di polipropilene (è opportuno stoccare almeno due provette per campione) che possono essere conservate a $2-8^{\circ} \mathrm{C}$ fino ad un massimo di 72 ore o congelate $\mathrm{a}-80^{\circ} \mathrm{C}$. Possono essere sottoposti a non più di 2 cicli di congelamento/scongelamento.

\section{Ricerca quantitativa di HIV RNA in campioni di sangue}

La raccolta va fatta in provetta con EDTA (con $\mathrm{ACD}$ si ottengono concentrazioni più basse), mai eparina. Il plasma va separato entro 6 ore dal prelievo e trasferito in provetta sterile in polipropilene (almeno due provette per campione). Può essere conservato a temperatura ambiente per 24 ore, a $2-8^{\circ} \mathrm{C}$ fino ad un massimo di 5 giorni, oppure congelato a $-70^{\circ} \mathrm{C}$. I cicli di congelamento/scongelamento non devono mai essere superiori a 3 .

\section{Ricerca quantitativa di CMV DNA in campio- ni di sangue}

La raccolta va fatta in provette con EDTA ed il plasma deve essere separato entro 24 ore dal prelievo e trasferito in provetta sterile di polipropilene. Può essere conservato a temperatura ambiente per 24 ore o a $2-8^{\circ} \mathrm{C}$ fino ad un massimo di 5 giorni o congelati a $-70^{\circ} \mathrm{C}$.

I cicli di congelamento/scongelamento non devono mai essere superiori a 3 .

Il trasporto dei campioni, per tutti i test citati deve essere fatto nel modo seguente:

- sangue intero: $2-25^{\circ} \mathrm{C}$

- siero o plasma: $2-8^{\circ} \mathrm{C}$ o congelati a $-70^{\circ} \mathrm{C}$

\section{Ricerca qualitativa e genotipizzione di HPV} Campioni:

- liquido seminale, urine primo mitto, biopsie (tratto urogenitale e canale anale) raccolti in contenitore sterile. Il liquido seminale va diluito $1: 10$ in terreno di trasporto $(9 \mathrm{gr} \mathrm{NaCl}, 1,21 \mathrm{~g}$ Tris- $\mathrm{HCl}, 1000 \mathrm{ml}$ di acqua distillata, $\mathrm{pH} 8$ (con $\mathrm{HCl} 1 \mathrm{~N}$ ), con aggiunta di $10 \mathrm{ml}$ di soluzione contenente penicillina $10000 \mathrm{U} / \mathrm{ml}$, streptomicina $10000 \mu \mathrm{g} / \mathrm{ml}$ e fungizone $25 \mu \mathrm{g} / \mathrm{ml}$ ) e congelato a $-20^{\circ} \mathrm{C}$. Le urine devono essere centrifugate ed il pellet va risospeso in terreno di traspor- 
to e congelato a $-20^{\circ} \mathrm{C}$. Gli altri campioni vanno congelati a $-20^{\circ} \mathrm{C}$.

- tamponi o scrapings endocervicali, vaginali, vulvari, anali e perianali (nella femmina), tamponi uretrali, da solco balano-prepuziale, da glande, scrapings da lesione anale e perianale del pene del maschio raccolti in $1,5 \mathrm{ml}$ di terreno di trasporto e congelati a $-20^{\circ} \mathrm{C}$.

I campioni in terreno di trasporto, se processati entro 24 ore possono essere conservati a $4^{\circ} \mathrm{C}$ Trasporto: $2-25^{\circ} \mathrm{C}$

\section{Ricerca qualitativa RNA del SARS CoV (Coronavirus della SARS) \\ Campioni ottimali:}

- Tampone nasofaringeo + tampone orofaringeo e campione di sangue (siero o plasma): durante la prima settimana di malattia. I tamponi devono essere in dacron o rayon (mai calcio alginato: può inibire la reazione di amplificazione), con supporto di plastica (mai di legno: può inibire la reazione di amplificazione) e vanno subito immessi in $2 \mathrm{ml}$ di terreno di trasporto per virus)

- Tampone nasofaringeo + tampone orofaringeo e campione di feci: dopo la prima settimana di malattia.

Altri possibili campioni:

- aspirato nasofaringeo (raccolto con 1-1,5 $\mathrm{ml} \mathrm{di}$ soluzione fisiologica non batteriostatica a pH 7), aspirato tracheale, liquido da lavaggio broncoalveolare, liquido pleurico, urine, tessuti bioptici o autoptici da raccogliere in contenitori sterili.

Il sangue va raccolto in quantità di $5-10 \mathrm{ml}$ ed immesso in provetta sterile con EDTA (per separare il plasma) o in provetta sterile senza anticoagulante (per separare il siero).

Le feci vanno raccolte in contenitori sterili.

Se i campioni vengono analizzati entro 48 ore dal prelievo si possono conservare a $4^{\circ} \mathrm{C}$, altrimenti vanno congelati a $-70^{\circ} \mathrm{C}$, a $-20^{\circ} \mathrm{C}$ per brevi periodi di tempo.

Trasporto:

va fatto a $4^{\circ} \mathrm{C}$, in ghiaccio secco se spedito ad altra sede. Il sangue va trasportato e spedito a $4^{\circ} \mathrm{C}$ (linee guida CDC).

\section{Ricerca Chlamydia trachomatis in campioni del tratto genitale ed urine \\ Campioni:}

- tamponi endocervicali o uretrali vanno raccolti in terreno di trasporto (fornito con i kit commerciali) e possono essere conservati a $2-8^{\circ} \mathrm{C}$ per un massimo di 7 giorni o a $-70^{\circ} \mathrm{C}$ per un massimo di due mesi.

- urine: $10-15 \mathrm{ml}$ di urine in contenitore sterile senza conservanti. Possono essere conservate a $\mathrm{T}$ ambiente per 24 ore o a $2-8^{\circ} \mathrm{C}$ per un massimo di 4 giorni o a $-70^{\circ} \mathrm{C}$ per due mesi.

Trasporto:

a $2-8^{\circ} \mathrm{C}$ o congelati. Le urine possono essere trasportate a temperatura ambiente se consegnate entro 24 ore dalla raccolta. Se non consegnate entro le 24 ore vanno conservate a $2-8^{\circ} \mathrm{C}$ fino al momento della spedizione (che deve essere comunque effettuate entro 4 giorni)

\section{Ricerca DNA di Chlamydia pneumoniae}

Campioni:

- sangue raccolto in provetta sterile con ACD che viene subito trattato per separare i linfociti (con Ficoll Paque)

- scraping da naso o gola stemperato in $1,5 \mathrm{ml} \mathrm{di}$ terreno di trasporto 2SP (saccarosio 13,7 g tamponato con $\mathrm{K}_{2} \mathrm{HPO}_{4} 0,4176 \mathrm{~g}$, e $\mathrm{KH}_{2} \mathrm{PO}_{4}$ $0.2176 \mathrm{~g}$ a $\mathrm{pH} 7$, acqua distillata $200 \mathrm{ml}$, siero bovino fetale $22 \mathrm{ml}$, streptomicina $11 \mathrm{mg}$, vancomicina $22 \mathrm{mg}$, fungizone $1 \mathrm{mg}$ )

- liquido da broncolavaggio in contenitore sterile

- biopsie in contenitore sterile

Tutti i campioni vanno trasportati al laboratorio nel più breve tempo possibile a $2-8^{\circ} \mathrm{C}$ e conservati a $-20^{\circ} \mathrm{C} /-70^{\circ} \mathrm{C}$. Se il campione viene processato entro 24 ore dal prelievo può essere conservato a $2-8^{\circ} \mathrm{C}(\mathrm{ad}$ eccezione del sangue che va trattato subito)

\section{Ricerca acidi nucleici di Mycobacterium tuber- culosis \\ Campioni:}

espettorato spontaneo o indotto, liquido da lavaggio bronchiale o da lavaggio broncoalveolare raccolti in contenitore sterile. Devono essere liquefatti, decontaminati e concentrati secondo le indicazioni del CDC entro 24 ore dal prelievo. Possono essere conservati tra $-20^{\circ} \mathrm{C}$ e $-70^{\circ} \mathrm{C}$ per un massimo di 6 mesi (RNA)-8 mesi (DNA).

Trasporto:

i campioni devono essere trasportati entro 24 ore dal prelievo, a temperature comprese tra 2 e $25^{\circ} \mathrm{C}$ oppure congelati a $-20 /-70^{\circ} \mathrm{C}$

\section{CONCLUSIONI}

Le modalità di raccolta e conservazione dei campioni sono uno dei punti critici che condizionano pesantemente la qualità del risultato finale e sono a loro volta condizionate dalle peculiarità degli analiti da evidenziare. Per quanto riguarda le tecniche molecolari gli studi fino ad ora fatti hanno permesso di stilare degli schemi operativi in molti casi ormai consolidati. Gli esempi riportati si riferiscono alle metodiche molecolari più diffuse, in uso presso il nostro laboratorio e per le quali esiste ampia documentazione in letteratura. Va comunque sottolineato che la situazione è in con- 
tinua evoluzione, per cui è necessario un monitoraggio continuo delle innovazioni tecnologiche e metodologiche ed una particolare attenzione alle modifiche che vengono frequentemente apportate e che possono coinvolgere le modalità di raccolta e conservazione del campione. È importante infatti, data la rapidità con cui aumentano le conoscenze, essere pronti per cogliere i cambiamenti, per adeguarsi rapidamente e soddisfare nel modo migliore le necessità dei pazienti.

\section{BIBLIOGRAFIA}

1. Bourlet T, Levy R, Maertens A, et al. Detection and Characterization of Hepatitis C Virus RNA in seminal plasma and spermatozoon fractions of semen from patients attempting medically assisted conception. J Clin Microbiol 2002 Sept; 40(9): 3552-5.

2. Cushwa WT, Mediano JF. Effects on blood storage time and temperature on DNA yield and quality. Biotchniques 1993 Feb; 14(2): 204-7.

3. De Moreau de Gerbehaye AI, Bodeus M, Robert A, Hosmans Y, Goubau P. Stable hepatitis C virus RNA detection by RT-PCR during four days storage. BMC Infectious Diseases 2002; 2: 22-7.

4. Dickover RE, Herman SA, Saddiq K, Wafer D, Dillon $\mathrm{M}$, Bryson YJ. Optimization of specimen-handling procedures for accurate quantitation levels of Human Immunodeficiency Virus RNA in plasma by reverse transcriptase PCR. J Clin Microbiol 1998 Apr; 36 (4): 1070-3.

5. Farkas DH, Kaul KL, Wiedbrauk DL, Kiechle FL. Specimen collection and storage for diagnostic molecular pathology investigation. Arch Pathol Lab Med 1996; 120: 591-6.

6. Ginocchio CC, Wang XP, Kaplan MH, et al. Effects of specimen collection, processing and storage conditions on stability of Human Immunodeficiency Virus type 1 RNA levels in plasma. J Clin Micorbiol 1997 Nov; 35 (11): 2886-93.

7. Holguin A, Williams 1, Castilla J, Soriano V. Influence of time and storage conditions on plasma HIV viral load measurements. Antivir Ther 1997 Dec; 2(4); 265-8.

8. Holodniy M, Rainen L, Herman S, Yen-Lieberman B. Stability of plasma Human Immunodeficiency Virus load in VACUTAINER PPT plasma preparation tubes during overnight shipment. J Clin Microbiol 2000 Jan; 38 (1): 323-6.

9. Kailash U, Hedau S, Gopalkrishna V, Katiyar S, Das BC. A simple "paper smear" method for dry collection, transport and storage of cervical cytological specimens for rapid screening of HPV infection by PCR. J Med Microbiol 2002; 51: 606-10.

10. Krajden M, Minor JM, Rifkin O, Comanor L. Effect of multiple freeze-thaw cycles on hepatitis B virus DNA and hepatitis $\mathrm{C}$ virus RNA quantification as measured with branched-DNA technology. J clin Microbiol 1999; 37: 1683-6.

11. Lahiri DK, Schnabel B. DNA isolation by a rapid method from human blood samples: effects pf $\mathrm{MgCl} 2$, EDTA, storage time, and temperature on DNA yield and quality. Biochem Genet 1993 Aug; 31(7-8): 321-8.

12. Landi MT, Caporaso N. Sample collection, processing and storage. IARC Sci Publ 1997; (142). 223-36.
13. Miller JM: The impact of specimen management in microbiology. MLO Med Lab Obs 1998 May; 30(5): 28-34.

14. Solmone M, Girardi E, Costa F, Pupillo L, Ippolito G, Capobianchi M. Simple and reliable method for detection and genotyping of Hepatitis C virus RNA in dried blood spots stored at room temperature. J Clin Microbiol 2002 Sept; 40 (9): 3512-4.

15. Schunemann HJ, Stanulla M, Trevisan M, Aplan PD, Freudenheim JL, Muti P. Short-term storage of blood samples and DNA isolation in serum separator tubes for application in epidemiological studies and clinical research. Ann Epidemiol 2000 Nov; 10(8): 538-44.

16. Tsui NBY, Ng EKO, Lo YMD. Stability of endogenous and added RNA in blood specimens, serum and plasma. Clin Chem 2002; 48 (10): 1647-53.

17. Watson JD, Hopkins NH, Roberts JW, Steitz JA, Weiner A. Molecular biology of the gene. Fourth Edition. Recce Gillen J Ed 1988; 1098-163.

18. Wilson ML. General principles of specimen collection and transport. Clin Infect Dis 1996 May; 22(5): 766-77. 